\title{
Exploration of new generation city bus informationization system based on Internet of Things and cloud computing technology
}

\author{
Hua Zhao \\ Shandong Xiehe University, Jinan Shandong, 250000, China
}

Keywords: Internet of Things, Cloud computing technology, City bus, Informationization system.

\begin{abstract}
This article starts from the importance of Internet of Things and cloud computing technology in new generation city bus informationization system, and makes comprehensive analysis on the overall design of the informationization system and the subsystem for the purpose of laying solid foundation for the comprehensive development of Chinese city bus field.
\end{abstract}

\section{Introduction}

With the continuous increase of city population, there are bigger city traffic pressure. In this case, it is critical to actively strengthen the construction of city bus system. City bus informationization system is the certain outcome of urban development and progress of information technology. In internal system through the effective application of Internet of Things and cloud computing technology, each sub system can realize high degree data sharing to lay solid foundation for improving the efficiency of city bus transit. This article makes studies on new generation city bus informationization system based on Internet of Things and cloud computing technology for the purpose of laying solid foundation for the long-term development of Chinese city bus informationization construction.

Importance of Internet of Things and cloud computing technology in new generation city bus informationization system

In recent year under the background of ever-developing social economy, China has expanded its urban scale in the process of active modernization construction. Limited by land resources, common occurrence of traffic congestion, illegal parking, etc. are bad to improve the urban environment quality, and also seriously restrained urban sustainable development [1]. But the generation and scientific application of Internet of Things and cloud computing technology have greatly made $u$ for the defects in urban development. National policy support has promoted the combination between city transportation and advanced technologies, and laid solid foundation of the construction of urban city informationization system.

Overall design of new generation city bus informationization system based on Internet of Things and cloud computing technology

\section{Data center}

City bus enterprises must construct data center based on the practical condition of local bus application during the operation process. Data center should guarantee that each subsystem functions inside the whole city informationization system can be fully developed and make sure information can be shared in various subsystems. In this case, the computer room system, center network system and non-structural data system will be important components of the data center.

During the operation process of data center, the greatest function is to store and analyze mass of data. Internet of Things and cloud computing technology is the technological foundation of the new 
generation city bus data center so that it can effectively carry out communication work ${ }^{[2]}$. However, communication transmission forms are different in various subsystems, so multiple communication protocols should be compatible. Based on this, it is necessary to promote the rapidity and timeliness to be fully reflected in the process of applying cloud computing. But in the process of building new generation city bus informationization system, stability and security shows significant importance in communication system. When connecting each subsystem, the neurological function of network can be fully developed and form between subsystem data through network and interactive function. Because of this, city bus informationization system must pay attention to stability, security and high efficiency of network system in the construction and development of city bus informationization system.

\section{Overall design}

In actual application of APTS system, it is necessary to understand the current condition of Chinese city bus informationization system for fully mastering each item of city bus system. Normally, each section inside city bus informationization system shows eight functions. Thus, start with the eight subsystems including security system, internal management system and passenger service system when carrying out researches ${ }^{[3]}$. It's worth noting that function system is an important component to constitute subsystem and there exist different between each function systems.

\section{Subsystem design of new generation city bus informationization system based on Internet of Things and cloud computing technology}

\section{Operation and dispatching system design}

Daily operation management system and intelligent dispatching system are important components of the system, mainly responsible for guarantee the normal function of operation.

Firstly, daily operation management system. During the operation process, it can effectively make statistic and organization of city bus operation data and make unified calculation of various consumption produced in the process of city bus operation including the consumption and labor power in the production process so as to identify the city bus operation costs and work out the economic profits earned by employees ${ }^{[4]}$. During the system operation process, it can effectively connect the operation guarantee and operation dispatching system, and make comprehensive statistic of all data produced in city bus informationization system.

Secondly, intelligent dispatching system. Intelligent dispatching web server, vehicle scheduling, monitoring and dispatching system are important components in this system. And the terminal mobile unit as the intelligent dispatching web server can fully dispatch the vehicle GPS speed, vehicle running status during the operation. And data storage and work flow management and departing dispatching work is under the charge of monitoring and dispatching system.

\section{Operation guarantee system design}

In the process of integrating informationization management with oil , material management and vehicle maintenance in city bus field, the operation guarantee system is produced and constituted by maintenance, refuel (refilling) and material management system together.

In city bus operation, large amount of materials require for in-out stock management so that the application of RFID technology in material management system can help visualization to be realized in the in-out stock management. In this case, the bus enterprise can master and control real-time material consumption quantity and highlight the characteristic of refined management. Thus, during the bus enterprise operation, it is no need to store surplus materials in a large scale and the reduction of unused materials can lay good foundation for saving and keeping costs ${ }^{[5]}$. Through real-time visualized material monument, enterprises can master the current status of accessory consumption during bus operation process, and make following statistics of production consumption, which can help reduce the bus enterprise operation costs and increase economic benefits. In bus operation, refuel 
or refilling is crucial procedure and during the management of this procedure, it is necessary to make full application of non-contact RFID technology, i.e. enterprises should install the skid-mounted gas station first so that refuel or refilling can be automatically by the driver. The backend database can make real-time record of the oil consumption of buses. During the process of making statistics and analysis on the actual oil consumption, the function of operation statistic system can be fully developed ${ }^{[6]}$.

In daily bus ordinary maintenance, it is necessary to apply the maintenance management system which can apply the efficiency supervision, production statistics, quality management and maintenance management to vehicles, and meanwhile display the specific bus maintenance process, which can improve the bus maintenance quality and efficiency and provide large amount of reliable information for bus late-stage operation and maintenance.

\section{Emergency processing system design}

During the city bus operation process, the chief dispatching operation and emergency handling are completed by emergency processing system which owns many components including bus dispatching directing center system and bus trunked system.

It's worth noting that the operation system of city bus is very open, auxiliary and inflexible, but the road information in each area of city are changing at any moment ${ }^{[7]}$. It is because of the strong uncertainty that the city bus operation strategies based on historical data cannot be effectively implemented with low feasibility. When traffic accidents and other emergencies happened, public security will reduce. It can be seen that in the process of building new generation city bus informationization system based on Internet of Things and cloud computing technology, it is urgent to actively construct emergency processing system.

In front of emergencies, the system must respond at once and related emergency response pre-planned scheme contains key steps for events handling which can help related working staffs to deal with various accidents orderly and timely judge the event type, and make grade division on event. Different emergency accidents with different grades should be handled in different ways. And the detailed accident handling procedures should include the contact flow of bus units and related staffs so as to utmost increase handling speed and quality and reduce the economic damage and personal security damage to the lowest.

It's worth noting that during applying the above handing methods, the communication methods must be with strong stability, convenience and multiple functions. In this way, the system function can be fully developed.

\section{Passenger service system design}

In the process of system operation, it can provide important travel information to passengers so that their travel have more selectivity and timeliness and provide most convenience for passenger travel. The system is made up of several parts including mobile phone inquiry system and multi-media stop board system. In the process of sample estimate hotline query data and bus travel strategic data, comprehensive use traffic real-time stream data and public transport passenger flow data to make clear division on important station and bus routes in city citizens' daily travel, and make analysis on the purpose, and environmental limit of citizen travel, and formulate citizen travel strategy based on the existing bus transport capacity. During the process, various advanced information technologies are applied including multi-media, Internet of Things, and wireless broadband technology ${ }^{[8]}$. When collecting information, it has strong instantaneity and data mining ability based on advanced technology, which can improve the scientificity and feasibility of bus travel strategy through analyzing mess of data and help improve citizen travel environment and lay solid foundation of China to realize "Green Travel".

\section{Security system design}

During implementing effective regulation of city bus system and improving city bus security ability, the importance of security protection system can never be ignored. Effective application of this 
system can improve the security of city bus operation and provide guarantee for people's secure travel. Electronic guard tour system, security monitoring system and 3G video monitoring system are important components.

Electronic guard tour system's major function is to carry out patrol inspection for the purpose of improving night security level. In the integral management, it owns characteristics of multi-terminals and distribution, i.e. to make concentrated issuing of patrol plan in actual operation and make targeted setting and patrol arrangement based on bus enterprises' demand. Meanwhile, it can lay solid foundation for seamless night regulation and adjust patrol plan ${ }^{[9]}$.

Digital monitoring technology is the basis for security monitoring system operation, collection monitoring system and station supervision system are important components of the system. In the system operation, the transmission of digital video signal requires to make full use of network and the supervision costs will reduce. Most importantly, related working staffs' workload can be largely reduced when carrying out troubleshooting work.

3G technology is the basis of 3G video monitoring system mainly aiming at the condition side carriage during developing its real-time supervision. In this way, higher security supervision function can be effectively applied to public sites. Meanwhile, the system is networking with 110 alarm center. During city operation, it can master the real-time bus transit, bus station status comprehensively from different dimensions in the whole journey. Meanwhile during integrating the e-map, the bus GPS dynamics can be profoundly analyzed and 110 alarm system can respond at the first time when accidents happen spreading important supervision information to network to realize the online spot view and real-time network supervision.

\section{Conclusion}

To sum up, in urban continuous development, city bus is forming a tremendous system which is influenced by many factors. In the process of strengthening the system management, traditional management method based on artificial experience cannot satisfy the development demand of city bus informationization system. The generation and effective application of Internet of Things and cloud computing technology have improved the operation and management efficiency of new generation city bus informationization system, improved the traffic resource utilization rate, and indicated the direction of future construction of Chinese city bus system.

\section{Acknowledgement}

Shandong Provincial Soft Science Research Project "Studies on city bus priority development strategy based on Internet +--take Jinan City as example". Project No. $2016 R K B 01425$

\section{Reference}

[1] Teng Jing, Yang Xiaoguang, City bus supervisory information system demand analysis and function design,Urban Transport of China, 2015,08(3):72-78.

[2] Cai Ou. GOOGLEMAP based public transport RTMS design and implementation,Tianjin University, 2013.

[3] Yang Tianming, Huang Yinxian. Theory and practice of applying information technology to build modernized city bus network---Progress and target of Xi'an Municipal city bus information networking, Collections of new age Chinese urban public transport modernization forum.2014:61-64.

[4] Chen Shahui. Operational analysis on multi-source data based public transit system and studies on evaluating key technology, Beijing University of Technology, 2014. 
[5] Bai Mingzhe. Design and implementation of WebGIS based Jiaozuo City bus sytem, Henan Polytechnic University, 2015.

[6] Wu Dehua, Yang Bing, Fu Weijun. MapGIS IGServer based two and three dimensions integration human meridian information systemdesign, Bulletin of Surveying and Mapping, 2014(10):121-124.

[7] Tao Xidong. International experience and inspiration from cosmopolitan cities' governance of traffic congestion - take Hong Kong as example, Innovation, 2016,10(1):106-113.

[8] Qian Fang. Studies on public transport priority policy in county-level cities of Shanghai-Hangzhou metropolitan economic zone-Take Tongxiang City as example, Shanghai Jiaotong University, 2014.

[9] Xian Hengsen. Studies on Nanning public transport priority development strategy from the public policy perspective, Guangxi University, 2015. 